\title{
Correspondence
}

\section{A substitute for "small airway disease"?}

SIR,-I was very interested by the editorial of Drs CM Fletcher and NB Pride "revisiting" the definitions of emphysema, bronchitis, and airflow obstruction 25 years after the CIBA Guest Symposium (February 1984, p 81). There is no doubt for me that "the term chronic bronchitis should be used only to denote chronic or recurrent bronchial hypersecretion." Ten years ago I was among the Romanian pulmonologists stressing the ambiguous character of the term chronic bronchitis and calling for its redefinition.' With regard to "non-emphysematous irreversible airway obstruction," although agreeing that "small airways disease" is unsuitable, I was somewhat surprised to see that "peripheral airway obstruction" was not considered (and discussed) as an alternative. "Peripheral" could be defined as the airways distal to the XIII-XIVth generation according to Weibel. ${ }^{2}$ The term is currently used in French publications. ${ }^{3}$

I am unable to say who and when used this term for the first time, but by 1970 Macklem and coworkers studied the "stability of peripheral airways," 4 and in 1973 the same team evaluated the changes in particulate deposition in the lung with "peripheral airway obstruction."

Why not "peripheral airway obstruction" then?

DB TECULESCU

INSERM Unité 14, CHU Brabois, 54511 Vandoeuvre, Nancy, FRANCE

1 Racoveanu C, Teculescu D, Manicatide M, Nicolaescu V. What is meant by "chronic bronchitis"? Santé Publique (Bucharest) 1974;3:343-50.

2 Weibel ER. Morphometry of the human lung. New York: Academic Press, 1963.

3 Teculescu D, Sadoul P. L'obstruction des voies aériennes périphériques. Aspects cliniques, tableau radiologique, incidences thérapéutiques. Rev Pneumologie Clinique 1984;40:3540 .

${ }^{*}{ }^{*}$ This letter was sent to the authors, who reply below.

SIR,-We are grateful to Dr Teculescu for his support for our insistence that British authors and chest physicians should confine their use of the term chronic bronchitis to chronic or recurrent bronchial mucous hypersecretion.

We agree that the term peripheral airway obstruction is an improvement on "small airway disease," but it does not distinguish between narrowing due to primary disease of the airway wall or lumen and narrowing which is secondary to the loss of airway distending forces and lung recoil that accompanies emphysema. In the latter case there may be no pathological change in the airway wall or lumen. As we were seeking a term to describe non-emphysematous irreversible obstructive disease of the peripheral airways themselves, we preferred the term obstructive bronchiolitis, which, although not quite accurate anatomically, does indicate the presence of inflammatory change in the airway itself. We would be happier to use peripheral air- way obstruction in a broader sense to describe peripheral airway narrowing of whatever cause-obstructive bronchiolitis, contraction of airway muscle, secondary to loss of extra-airway distending forces or any other cause which may be discovered. The definition of a "peripheral" airway also raises some problems - should it be defined in terms of structure (absence of cartilage in the wall), generation number, or size of lumen at a standard distending pressure? The asymmetry of airway branching in the lung unfortunately makes the Weibel generation numbers inexact (or inaccurate).

CM FLETCHER

NEIL B PRIDE

Royal Postgraduate Medical School, Hammersmith Hospital, London W12 OHS

\section{Standardised lung function testing}

SIR,--In your editorial 'Standardised lung function testing' (December 1984;39:881-6) Dr G Laszlo summarises the consequences of changing from the reference values given by Cotes ${ }^{1}$ to the European Coal and Steel Community (ECSC) figures. ${ }^{2}$ Overall he considers the changes are relatively slight. From the table, however, changes for transfer coefficient (KCO) of $+0.4 \mathrm{mmol} \mathrm{min}^{-1} \mathrm{kPa}^{-1} \mathrm{1}^{-1}$ for men and +0.25 to +0.38 for women represent standard deviation changes of 1.48 for males and 1.9-1.25 for females. These are considerable deviations and would materially affect the reporting of Kco lung function data in most UK laboratories adopting the ECSC figures. Is there an explanation for these apparently large differences in transfer coefficient formulae?

ALAN J WILLIAMS Respiratory Medicine, Royal Liverpool Hospital, Liverpool L7 $8 X P$

1 Cotes JE. Lung function: assessment and applications in medicine. 4th ed. Oxford: Blackwell Scientific Publications, 1979.

2 Quanjer PH, ed. Standardized lung function testing. Bull Eur Physiopathol Respir 1983;19(suppl 5):1-95.

\section{*This letter was sent to Dr Laszlo, who replies below.}

SIR,-I am grateful to Dr Williams for encouraging me to look at the problem of the high predicted values for transfer factor for carbon monoxide divided by lung volume (TLVA, KCO) yielded by the summary equations quoted in the ECSC document "Standardized Lung Function Testing."

TL/VA has never seemed to me to be a satisfactory screening test for abnormality. Thco measurements are quite repeatable because it is virtually constant provided that the measurement is made at an alveolar volume of $80-95 \%$ of total lung capacity (TLC).' It follows that $\mathrm{TL} / \mathrm{VA}_{\mathrm{A}}$ is dependent on lung volume and may vary by $20 \%$ when VA is $80-100 \%$ of TLC.

It is therefore not surprising that a wide range of predicted values has been published. The exact procedure 
used is not always described in publications providing reference data. Calculation of VA from predicted values of $\mathrm{TL}$ and TL/VA for a standard individual shows that breath holding volume was appropriate (near to $90 \%$ of TLC) in most of the studies quoted except that of van Ganse ${ }^{2}$; in this group VA was apparently low and TL/VA correspondingly high.

Two other, correctable, sources of error in the small number of studies quoted were overlooked by the authors of the ECSC document. Firstly, the formula for TUVA in the paper by Hall et al, ${ }^{3}$ which is transcribed into the document, yields values that are obviously incorrect. Secondly, there has never been any formal agreement about the exact expression for Kco. Those preferring the form TL/VA have divided TLCo by VA(BTPS), following the convention that lung volumes are to be expressed in BTPS units. Those who have regarded the index as a version of Krogh's transfer coefficient have sometimes divided TL by VA(STPD), yielding a result which is systematically higher by $20 \%$. This accounts for the high value obtained by Teculescu and Stanescu, ${ }^{4}$ also uncorrected in the ECSC document.

There are therefore three reasons why the ECSC summary equations for Kco (TV/VA) yield higher values than appear acceptable. The first (low VA) is difficult to surmount. It follows that for reference purposes and as a screening test for normality TLCO is much more useful than TL/VA and the latter should probably not be used in this context.

I would like to clarify the ambiguous heading to the table in the editorial. The figures given are those to be added to the values obtained from Cotes; 5 they are not the arithmetical differences between the values obtained from Cotes and those derived from the ECSC formula.

G LASZLO

Respiratory Department Bristol Royal Infurmary Bristol BS2 $8 \mathrm{HW}$

1 Frans A, Francis CH, Stanescu D, Nemery JB, Prignot J, Brasseur L. Transfer factor in patients with emphysema and lung fibrosis. Thorax 1979;33:539-40.

2 van Ganse WF, Ferris BG Jnr, Cotes JE. Quoted by Quanjer PH, Standardized lung function testing. Bulletin Europeen de Physiopathologie Respiratoire (Clinical Respiratory Physiology) 1983; 19;suppl 5:82.

3 Hall AM, Heywood C, Cotes JE. Lung function in healthy British women. Thorax 1979;34:359-65.

4 Teculescu DB, Stanescu DC. Lung diffusing capacity: normal values in male smokers and non-smokers using the breathholding technique. Scand J Resp Dis 1970;51:137-49.

5 Cotes JE. Lung function: assessment and application in medicine. 4th ed. Oxford: Blackwell Scientific Publications, 1979.

\section{Notices}

\section{British Lung Foundation grants}

The newly established British Lung Foundation is now in a position to invite applications for equipment grants for up to $£ 5000$ from its research fund. Application forms may be obtained from British Lung Foundation, 12a Onslow Gardens, London SW7 3AP, and must be returned by 31 July 1985.

\section{Current clinical managment of cystic fibrosis}

An all day symposium on this subject will be held at the Royal Society of Medicine, London, on Friday 25 October 1985. Further information may be obtained from the Honorary Secretary of the Section of Paediatrics, Dr TJ David, Department of Child Health, Booth Hall Children's Hospital, Charlestown Road, Blackley, Manchester M9 2AA.

\section{Current concepts in pulmonary pathology}

A postgraduate course on current concepts in pulmonary pathology will be held at the Massachusetts General Hospital, Boston, Massachusetts, USA, from 21 to 25 October 1985. Further information may be obtained from Department of Continuing Education, Harvard Medical School, 25 Shattuck Street, Boston, Massachusetts 02115,

\section{Dr HM (Bill) Foreman Memorial Fund}

The trustees of the Dr HM (Bill) Foreman Memorial Fund invite applications for grants relating to study in respiratory disease. Limited funds are available for registered medical practitioners to assist in travelling to countries other than their own to study respiratory disease, and also for support of clinical research abroad. Intending applicants should write for further details to Dr BH Davies, Sully Hospital, Sully, South Glamorgan CF6 2YA.

\section{Indian Chest Society: Fifth National Congress of Respirat- ory Diseases}

The Fifth National Congress of Respiratory Diseases will be held on 12-15 December 1985 at SMS Medical College, Jaipur, India. Those interested in attending the congress should contact Dr US Mathur, Secretary General, FNCRD, 18 Shivaji Marg, Diggi House, Jaipur 302004 , India. 